METZLER LITERATUR CHRONIK 
Volker Meid

\section{Metzler Literatur Chronik}

Werke

deutschsprachiger

Autoren

Verlag J. B. Metzler

Stuttgart - Weimar 


\title{
Inhaltsverzeichnis
}

\author{
Vorwort $\quad V$
}

Werke deutschsprachiger Autoren vom

8. Jahrhundert bis $1980 \quad I-697$

Literaturhinweise 699

Personen- und Werkregister

von Helmut G. Hermann 703

Die Deutsche Bibliothek - CIP-Einheitsaufnahme

Meid, Volker: Metzler-Literatur-Chronik :

Werke deutschsprachiger Autoren / Volker Meid

- Stuttgart ; Weimar : Metzler 1993

ISBN 978-3-476-00941-8

NE: HST

ISBN 978-3-476-00941-8

ISBN 978-3-476-03491-5 (eBook)

DOI 10.1007/978-3-476-03491-5

Dieses Werk einschlieBlich aller seiner Teile ist urheberrechtlich geschützt. Jede Verwertung außerhalb der engen Grenzen des Urheberrechtsgesetzes ist ohne Zustimmung des Verlages unzulässig und strafbar. Das gilt insbesondere für Vervielfältigungen, Übersetzungen, Mikroverfilmungen und die Einspeicherung und Verarbeitung in elektronischen Systemen.

(C) 1993 Springer-Verlag GmbH Deutschland

Ursprünglich erschienen bei J. B. Metzlersche Verlagsbuchhandlung und Carl Ernst Poeschel Verlag GmbH in Stuttgart 1993 


\section{Vorwort}

Die Metzler Literatur Chronik beschreibt in strikter Chronologie Werke der deutschen bzw. deutschsprachigen Literatur von der Zeit Karls des Großen bis zum Jahr I980, einem - vorläufigen - Schlußpunkt, der schon eine gewisse historische Perspektive ermöglicht. Bei der Konzeption der Chronik wurde von vornherein auf eine Gliederung nach Epochen verzichtet. Sie hätte sich, abgesehen von der Problematik mancher Epochenbegriffe und den damit verbundenen Schwierigkeiten der zeitlichen Abgrenzung, allein wegen der zahlreichen Überschneidungen nicht mit dem Prinzip einer konsequent chronologischen Ordnung vereinbaren lassen. Dessen Leistung besteht gerade darin, die Vielfältigkeit und Gegensätzlichkeit, ja Widersprüchlichkeit der literaturgeschichtlichen Vorgänge, das Nebeneinander der verschiedenen Strömungen und Generationen und die >Ungleichzeitigkeit< des Gleichzeitigen sichtbar zu machen, also eine Sicht der Literaturgeschichte zu bieten, die die Perspektive der literaturgeschichtlichen Erzählung mit ihrer auf Zusammenhänge und Entwicklungslinien gerichteten Darstellungsintention auf erhellende Weise ergänzt. Das bedeutet jedoch nicht, daß die Literatur Chronik nicht auf ihre Weise eine Charakteristik der literarhistorischen Epochen und Strömungen enthielte, übergreifende literarhistorische Zusammenhänge oder gattungs- und formgeschichtliche Traditionen einzubeziehen suchte: Dies geschieht an den einzelnen Werken, an signifikanten Beispielen für die jeweilige Fragestellung.

Die Chronologie der Werke orientiert sich am Jahr der ersten Publikation, sei es durch Aufführung, Vorlesung oder Druck. Nur in wenigen Fällen wurden Ausnahmen gemacht, etwa wenn Entstehungs- und Publikationsdatum extrem weit auseinanderliegen und der späteren Veröffentlichung selbst keine literarhistorische Aussagekraft zukommt (so wurde Herders Journal meiner Reise im Jahr 1769 , das einen entscheidenden Moment in Herders Biographie und die zum Sturm und Drang hinführende Aufbruchsstimmung dieser Jahre festhält, erst I846 gedruckt).

Bestimmend für die Aufnahme in die Literatur Chronik war nicht allein der ästhetische Rang der
Texte; neben dem traditioneller literarhistorischen Kanon ( $>$ Höhenkamm ), zu dem selbstverständlich auch Werke in lateinischer Sprache gehören, werden Texte berücksichtigt, die auf andere Weise literarhistorisch bedeutsam sind, sei es - beispielsweise - in ideologiekritischer oder rezeptionsgeschichtlicher Hinsicht. Dabei finden große Übersetzerleistungen ebenso Berücksichtigung wie - exemplarisch - Werke der Unterhaltungsliteratur. Zudem wurde im Einklang mit einem erweiterten Literaturbegriff versucht, den Bereich der nichtfiktiven Literatur wenigstens an ausgewählten Beispielen zu dokumentieren. Allerdings war dies, und hier zeigen sich die Grenzen des Unternehmens, angesichts der ständig wachsenden Produktion für die neuere Literatur immer weniger möglich.

Die einzelnen Artikel sind nicht schematisch angelegt; sie enthalten, im Einzelfall jeweils verschieden gewichtet, Informationen über Entstehung, Form, Inhalt, literarhistorischen Kontext, Deutungsmöglichkeiten und Wirkungsgeschichte. Ziel war dabei nicht nur die schnelle, sachliche und zuverlässige Information auf der Basis des gegenwärtigen Forschungsstands; über ihre Funktion als Nachschlagewerk hinaus möchte die Literatur Chronik durch ihren Darstellungsstil zum Lesen und Weiterlesen anregen und so dem Benutzer und Leser ein - hofft der Verfasser - facettenreiches Bild der Literatur und Kultur im deutschen Sprachraum vermitteln.

Eine wesentliche Hilfe dabei bietet das kombinierte Personen- und Werkregister Helmut G. Hermanns (Amherst/USA), das die Vielfalt des Buches erst wirklich erschließt (und auch die Lebensdaten der deutschsprachigen Autoren nennt). Dem Registermacher habe ich überdies für mannigfache Hinweise und Korrekturen zu danken. Entsprechender Dank gebührt Petra Wägenbaur, die das Buch als Lektorin betreute, Eva Eckstein, die beim Korrekturlesen half, und Bernd Lutz, ohne dessen Anregungen und Geduld die Literatur Chronik nie geschrieben bzw. beendet worden wäre.

Pruzilly, im Juli 1993 Volker Meid 